\title{
HUBUNGAN ANTARA TUNJANGAN PROFESI GURU DAN TAMBAHAN PENGHASILAN DENGAN CAPAIAN PEMBELAJARAN SISWA SEKOLAH MENENGAH PERTAMA NEGERI
}

\section{THE RELATIONSHIP BETWEEN TEACHER PROFESSIONAL ALLOWANCES AND ADDITIONAL INCOME AND STUDENT LEARNING ACHIEVEMENT OF PUBLIC JUNIOR HIGH SCHOOL}

\author{
Didik Biantoro \& Thia Jasmina \\ Fakultas Ekonomi dan Bisnis, Universitas Indonesia \\ JI. Salemba Raya No.4, RW.5, Kota Jakarta Pusat \\ E-mail: didik.biantoro@ui.ac.id; thia.jasmina@ui.ac.id
}

Naskah diterima tanggal: 13-09-2021 disetujui tanggal: 20-12-2021

\begin{abstract}
The Ministry of Finance of The Republic of Indonesia has allocated professional teacher allowance and additional income for teachers since 2010 and 2009, respectively. The additional income and allowances are expected to improve teacher welfare, competence, and professionalism so that student learning achievement will improve. This study aims to determine the relationship between professional teacher allowances as well as additional income for teachers and the student learning achievement of public junior high schools in Indonesia at the district level in 2018-2019 by applying quantitative panel data analysis. The results show that the budget realization of teacher professional allowances is positively related to the student learning achievement of public junior high schools. Whereas additional income has no relationship with the students' achievement. The control variables related to student learning achievement are the student-teacher ratio, the percentage of teachers with at least a bachelor's degree, per capita gross regional domestic product, and life expectancy. Meanwhile, the ratio of student-class and the percentage of poor people in the district have no relationship with the students' achievement. Professional teacher allowances indirectly increase student learning achievement by improving teacher competence and performance. Coordination enhancement of central and local governments to increase the budget realization of professional teacher allowances is expected upgrading teachers' competence and hence students' learning achievement will improve.
\end{abstract}

Keywords: professional teacher allowance, additional teacher income, student learning achievement

Abstrak: Kementerian Keuangan telah mengalokasikan tunjangan profesi guru dan tambahan penghasilan guru masing-masing sejak 2010 dan 2009. Tambahan penghasilan dan tunjangan tersebut diharapkan dapat meningkatkan kesejahteraan, kompetensi, dan profesionalisme guru sehingga dapat meningkatkan capaian pembelajaran siswa. Penelitian ini bertujuan untuk mengetahui hubungan tunjangan profesi guru dan tambahan penghasilan guru terhadap capaian pembelajaran siswa SMP Negeri di Indonesia tingkat kabupaten/kota tahun 2018-2019. Penelitian ini menggunakan analisis data panel. Hasil penelitian menunjukkan bahwa realisasi tunjangan profesi guru berhubungan positif dengan capaian pembelajaran siswa SMP Negeri. Sedangkan tambahan penghasilan tidak ada hubungannya. Variabel kontrol yang berhubungan dengan capaian pembelajaran siswa adalah rasio siswa-guru, persentase guru berpendidikan minimal sarjana, produk domestik regional bruto per kapita, dan angka harapan hidup. Sedangkan yang tidak berhubungan 
adalah rasio siswa-rombongan belajar dan persentase penduduk miskin. Tunjangan profesi guru secara tidak langsung meningkatkan capaian pembelajaran siswa melalui peningkatan kompetensi dan kinerja guru. Dengan koordinasi pemerintah pusat dan daerah untuk meningkatkan realisasi anggaran tunjangan profesi guru, diharapkan akan meningkatkan kompetensi guru yang akan meningkatkan capaian pembelajaran siswa.

Kata kunci: tunjangan profesi guru, tambahan penghasilan guru, capaian pembelajaran siswa

\section{PENDAHULUAN}

Dalam Undang-Undang Republik Indonesia Nomor 14 tahun 2005 (UU 14/2005) menerangkan bahwa guru bukan hanya sebagai pengajar, melainkan juga sebagai pendidik, pembimbing, pengarah, pelatih, penilai, dan pengevaluasi siswa. Oleh karena itu, capaian pembelajaran siswa merupakan tanggung jawab guru. Namun demikian, pemerintah juga perlu berinvestasi dalam meningkatkan capaian pembelajaran siswa. Pemerintah dapat melakukan investasi dari sisi penawaran dan sisi permintaan (Glewwe, Lambert, \& Chen, 2020). Salah satu investasi pemerintah untuk pendidikan dari sisi penawaran adalah dengan memberikan insentif kepada guru. Pemberian insentif tersebut bisa dengan kenaikan gaji atau tunjangan.

Di Indonesia, pemberian insentif kepada guru berupa tunjangan profesi guru untuk guru bersertifikat pendidikan dan tambahan penghasilan untuk guru PNS yang belum memiliki sertifikat pendidik. Tunjangan Profesi Guru menurut Peraturan Pemerintah Nomor 41 Tahun 2009 (PP 41/2009) diberikan sebagai penghargaan atas profesionalitas guru. Dana tunjangan dapat digunakan untuk kegiatan peningkatan kompetensi dan kesejahteraan guru sehingga proses pembelajaran lebih baik yang akhirnya capaian pembelajaran bisa meningkat. Tambahan penghasilan guru pun demikian. Hanya saja, tidak ada tujuan meningkatkan kompetensi guru. Berdasarkan Peraturan Presiden Nomor 52 Tahun 2009, tujuan pemerintah memberikan tambahan penghasilan bagi guru adalah meningkatkan gairah kerja dan kesejahteraan bagi guru Pegawai Negeri Sipil Daerah (PNSD) khususnya yang belum memiliki sertifikasi.

Tambahan penghasilan guru bagi PNSD akan meningkatkan motivasi dan disiplin guru sehingga memacu produktivitas dan menjamin kesejahteraan yang muaranya akan memberikan pelayan terbaik kepada siswa (Amnatu, Aunurrahman, \& Suib, 2013). Hal ini juga terdapat dalam syarat pencairan tambahan penghasilan guru di Peraturan Menteri Pendidikan dan Kebudayaan Nomor 19 tahun 2019 (Permendikbud 19/2019) yaitu hadir dan aktif mengajar serta memenuhi beban kerja sebagai guru PNSD.

Meskipun demikian, capaian pembelajaran siswa yang merupakan output dari pendidikan bukan hanya dipengaruhi oleh guru, melainkan ada beberapa faktor seperti input sekolah, karakteristik siswa, dan keluarga. Menurut Hanushek (2013) faktor tersebut digambarkan dalam bentuk fungsi produksi pendidikan yaitu:

$$
A=f(R, F, Z, \eta)
$$

Di mana $A$ adalah capaian pembelajaran siswa yang merupakan fungsi dari input sekolah termasuk guru ( $R$ ), keluarga ( $F)$, faktor lain seperti lingkungan, teman sebaya, atau struktur kelembagaan umum ( $Z$ ), dan elemen stokastik $(\eta)$. Secara garis besar faktor-faktor tersebut dapat dikategorikan dalam karakteristik sekolah dan karakteristik sosial ekonomi di lingkungan siswa tersebut.

Capaian pembelajaran yang dipelajari siswa dapat diukur melalui standarized test. Standarized test yang berlaku secara 
Didik Biantoro \& Thia Jasmina, Hubungan antara Tunjangan Profesi Guru dan Tambahan Penghasilan dengan Capaian Pembelajaran Siswa Sekolah Menengah Pertama Negeri

internasional adalah evaluasi Programme for International Student Asessment (PISA), yang merupakan tes membaca, sains, dan matematika. Di Indonesia belum ada tes secara nasional untuk tes tersebut. Program Asesmen Kompetensi Siswa Indonesia (AKSI) yang dirancang sesuai dengan standarized test secara internasional pun masih sebatas sampel, belum menyeluruh (dilaksanakan tahun 2016 dan 2019). Hingga tahun 2019, di Indonesia, hasil dari standardized test tersebut tersedia dalam data ujian nasional (UN). UN ini merepresentasikan kondisi dari setiap daerah berdasarkan wilayah pembagian urusan dalam UU Nomor 23 Tahun 2014 pasal 12. Pendidikan anak usia dini dan nonformal, SD, serta SMP kewenangan pemerintah kabupaten/kota. Urusan SMA, SMK, dan pendidikan khusus kewenangan pemerintah provinsi.

Di tingkat internasional, penelitian terkait dengan hubungan antara insentif guru dengan capaian pembelajaran siswa menunjukkan hasil yang beragam. Salah satu penelitian Cebula, Jr., \& Montez (2015) menunjukkan bahwa gaji dan kualitas guru mempunyai hubungan yang positif terhadap hasil pendidikan yang diukur melalui Academic Performance Index (API) di sekolah menengah di Los Angeles. Perbedaan gaji guru atau adanya insentif tersebut dapat meningkatkan kinerja guru (Jones, 2013). Dalam hal ini, siswa yang diajar oleh guru yang berkualitas tinggi atau memiliki kompetensi dan kinerja yang baik akan cenderung memiliki hasil belajar/prestasi yang baik pula (Metzler \& Woessmann, 2012; Kunter, Klusmann, Baumert, Richter, Voss, \& Hachfeld, 2013; Chetty, Friedman, \& Rockoff, 2014). Dengan demikian, secara tidak langsung tambahan gaji atau insentif yang didapatkan oleh guru akan memengaruhi kinerja atau hasil belajar siswa (Goldhaber \& Walch, 2012; Goodman \& Turner, 2013; Hendricks, 2014; Sojourner, Mykerezi, \& West, 2014; Balch \& Springer 2015; Hanushek, Piopiunik, \& Wiederhold, 2018).
Di sisi lain, ada beberapa penelitian tingkat internasional yang hasilnya berseberangan. Di antaranya penelitian Cowan \& Goldhaber (2018) yang menunjukkan bahwa insentif guru bersertifikat tidak ada hubungannya terhadap prestasi siswa. Hasil serupa juga ditunjukkan oleh Fryer (2013); Chelwa, Pellicer, \& Maboshe (2019); Speroni, Wellington, Burkander, Chiang, Herrmann, \& Hallgren (2020). Bahkan hasil penelitian dari Pugatch \& Schroeder (2018) dan Yeşilırmak (2019) menunjukkan bahwa peningkatan hasil belajar siswa hanya terbatas pada siswa yang keadaan sosial ekonominya lebih baik.

Di Indonesia, tunjangan profesi guru berhubungan positif terhadap capaian pembelajaran siswa (Jasmina, 2016; Idawati, 2017). Guru yang mendapat tunjangan profesi akan meningkatkan kualitas pembelajarannya (Idawati, 2017) dan meningkatkan kinerjanya (Widinugroho \& Modouw, 2016; Arifah, 2018), kompetensinya (Yuliandri \& Tahrun, 2017; Nua, 2020) dan juga kreativitasnya (Parsa, 2017). Dengan adanya peningkatan tersebut, akan meningkatkan prestasi belajar siswa (Azwar, Yusrizal, \& Ar, 2015; Pristiawaty, 2015; Hapsari \& Prasetio, 2017; Mahdalena, 2019; Nua, 2020; Meiliyani, Fitria, \& Puspita 2021). Di samping tunjangan profesi guru, hasil belajar siswa juga ada hubungannya dengan kondisi sosial ekonomi, kesehatan, dan lokasi tempat tinggalnya (Jasmina, 2016).

Penelitian BaKTI (2018) juga menunjukkan bahwa ada hubungan yang positif dari pembayaran tunjangan guru terhadap kinerja guru di wilayah timur Indonesia sehingga berdampak juga pada hasil belajar siswa. Rerata nilai pada tes Bahasa Indonesia telah meningkat dari 37 menjadi 50, dan Matematika dari 37,4\% menjadi $48,8 \%$. Persentase murid yang buta huruf menurun dari $12,2 \%$ ke $1,7 \%$, begitu juga buta angka yang mengalami penurunan dari 7,7\% menjadi 0,4\%. Laporan dari Kemendikbud (2019) terkait hasil pemantauan dan evaluasi 
Tunjangan Profesi Guru (TPG) 2019 juga menunjukkan hasil yang serupa, bahwa siswa yang diajar oleh guru yang mendapat tunjangan profesi sebesar $64 \%$ hasil pembelajarannya sangat baik, 33\% kriteria baik, dan 3\% cukup baik. Hal ini tidak terlepas dari peningkatan kompetensi yang diikuti oleh guru yaitu seminar, pendidikan dan pelatihan, presentasi karya ilmiah, maupun kegiatan Musyawarah Guru Mata Pelajaran (MGMP) yang $94 \%$ sangat baik dan $6 \%$ baik.

Meskipun demikian, beberapa penelitian menunjukkan bahwa tidak ada hubungan antara tunjangan profesi guru dengan capaian pembelajaran siswa. Salah satunya adalah dari Ree, Muralidharan, Pradhan, \& Rogers (2018) yang melakukan eksperimen terhadap 360 sekolah di 20 kabupaten di Indonesia. Eksperimen tersebut dilakukan dengan wawancara kepala sekolah, guru, dan siswa, serta melakukan tes independen terhadap pengetahuan guru dan hasil belajar siswa. Hasilnya menunjukkan bahwa kenaikan gaji guru mengurangi masalah keuangan dan guru puas dalam bekerja sehingga mempunyai banyak waktu untuk lebih fokus mengajar dan mengurangi pekerjaan lain di luar. Namun demikian, waktu yang tersedia tersebut tidak dimanfaatkan guru untuk meningkatkan keterampilannya. Di sisi lain hasil penelitian menunjukkan bahwa kenaikan gaji guru tidak berdampak pada hasil skor ujian siswa pada mata pelajaran Matematika, IPA, Bahasa Indonesia, dan Bahasa Inggris, baik di sekolah dasar maupun menengah. Sehingga tunjangan profesi guru tidak berhubungan dengan kenaikan capaian pembelajaran siswa. Penelitian lain menunjukkan bahwa tidak adanya perubahan pada hasil belajar siswa disebabkan tidak adanya perubahan kinerja guru setelah mendapatkan tambahan gaji atau tunjangan guru (Kusumawardhani, 2017; Astiti, Wilian, \& Sridana, 2018)

Selama ini, penelitian terkait dengan tunjangan guru menggunakan anggaran pendidikan atau anggaran TPG. Sehingga belum bisa menggambarkan tunjangan yang diterima oleh guru. Berbeda dengan sebelumnya, penelitian ini menggunakan data realisasi anggaran baik TPG maupun tamsil (tambahan penghasilan) pada tingkat kabupaten/kota yang didapatkan dari Kemendikbud. Realisasi TPG tersebut dibagi dengan data jumlah guru PNS daerah yang tersertifikasi dan tamsil dibagi dengan PNSD yang belum tersertifikasi sehingga bisa menunjukkan karakteristik rata-rata realisasi setiap kabupaten/kota. Di samping itu, penelitian ini menggunakan data UNBK yang teruji integritasnya. Data yang digunakan merupakan UNBK SMPN tahun 2018 dan 2019 yang sudah memasukkan soal-soal Matematika, Literasi, maupun Ilmu Pengetahuan Alam yang memerlukan daya nalar tinggi dan berstandar internasional atau yang dikenal dengan Higher Order Thinking Skills (HOTS). Penggunaan data SMP negeri bisa mewakili SMP di Indonesia karena sekitar $60 \%$ sekolah menengah pertama di Indonesia didominasi oleh sekolah negeri. Di samping itu, sekitar 74\% siswa bersekolah di SMP negeri (Kemendikbud, 2019).

Menurut data dari Kemendikbud (2021), permasalahan yang ada adalah rata-rata hasil Ujian Nasional Berbasis Komputer (UNBK) yang dimulai sejak 2015 selalu turun setiap tahun kecuali tahun 2018 ke 2019. Namun, selama lima tahun terakhir tidak mendapat rata-rata kategori baik (di atas 70), bahkan 3 tahun terakhir rata-rata hasil UNBK sudah masuk kategori kurang (di bawah nilai 55).

Oleh karena itu, tujuan dari penelitian ini adalah untuk mengetahui pengaruh tunjangan profesi guru dan penghasilan tambahan guru terhadap capaian pembelajaran siswa SMP di Indonesia tingkat kabupaten/kota tahun 20182019. Penelitian ini juga memberikan informasi yang penting bagi pemangku kebijakan untuk meningkatkan mutu pendidikan melalui realisasi tunjangan guru. 
Didik Biantoro \& Thia Jasmina, Hubungan antara Tunjangan Profesi Guru dan Tambahan Penghasilan dengan Capaian Pembelajaran Siswa Sekolah Menengah Pertama Negeri

\section{METODE}

Kerangka berpikir dalam penelitian ini didasarkan pada penelitian-penelitian terdahulu, bahwa tunjangan profesi berhubungan positif terhadap capaian pembelajaran siswa melalui peningkatan kompetensi guru dan meningkatkan kinerja/ produktivitas guru yang ditunjukkan dari peningkatan proses pembelajaran. Begitu halnya dengan tambahan penghasilan guru yang dapat meningkatkan produktivitas guru dan meningkatkan capaian pembelajaran siswa. Kerangka berpikir tersebut terdapat pada flowchart Gambar 1 dan Gambar 2.
Penelitian ini merupakan penelitian kuantitatif dengan menggunakan analisis regresi data panel yaitu penggabungan antara pendekatan cross sectional dan time series. Tahapan penelitiannya yaitu identifikasi masalah, studi literatur, identifikasi variabel dependen maupun independen, pengumpulan data, dan analisis data. Pada analisis data panel perlu memilih model regresi terbaik, minimal dengan dua teknik estimasi model (Basuki, 2014) yang ditunjukkan oleh Gambar 3.

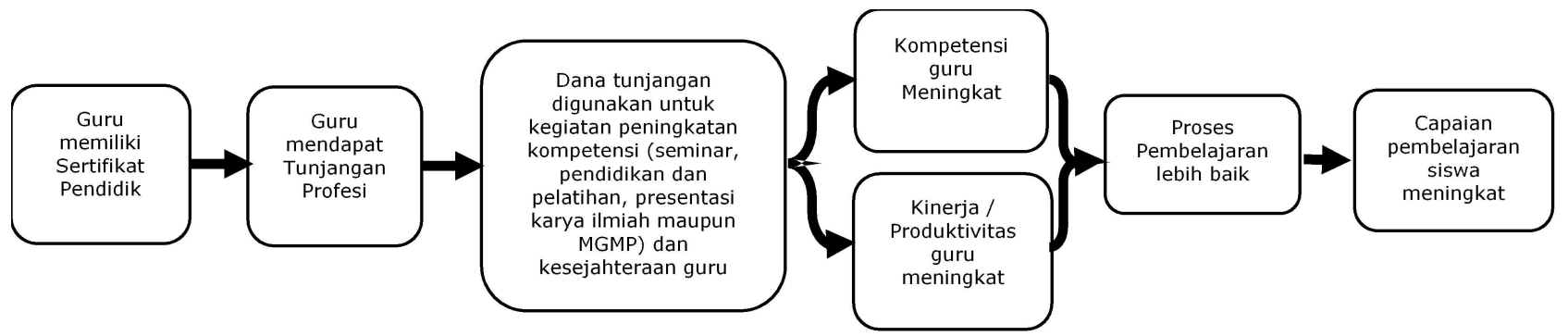

Gambar 1 Flowchart Hubungan Tunjangan Profesi Guru dengan Capaian Pembelajaran Siswa

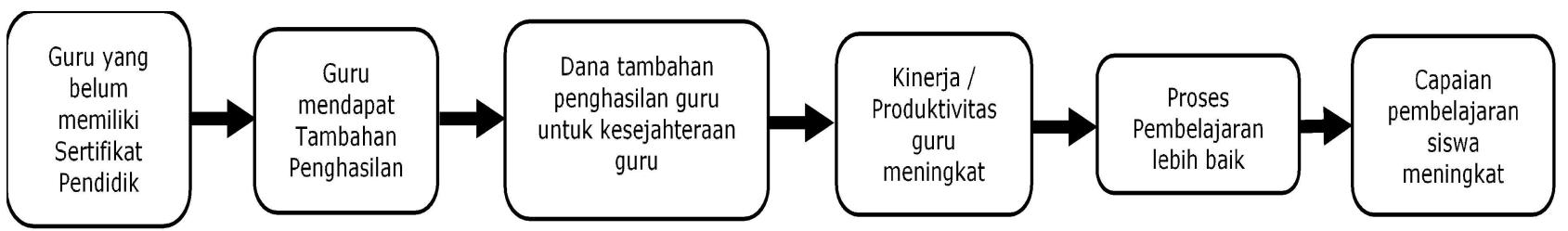

Gambar 2 Flowchart Hubungan Tambahan Penghasilan Guru dengan Capaian Pembelajaran Siswa

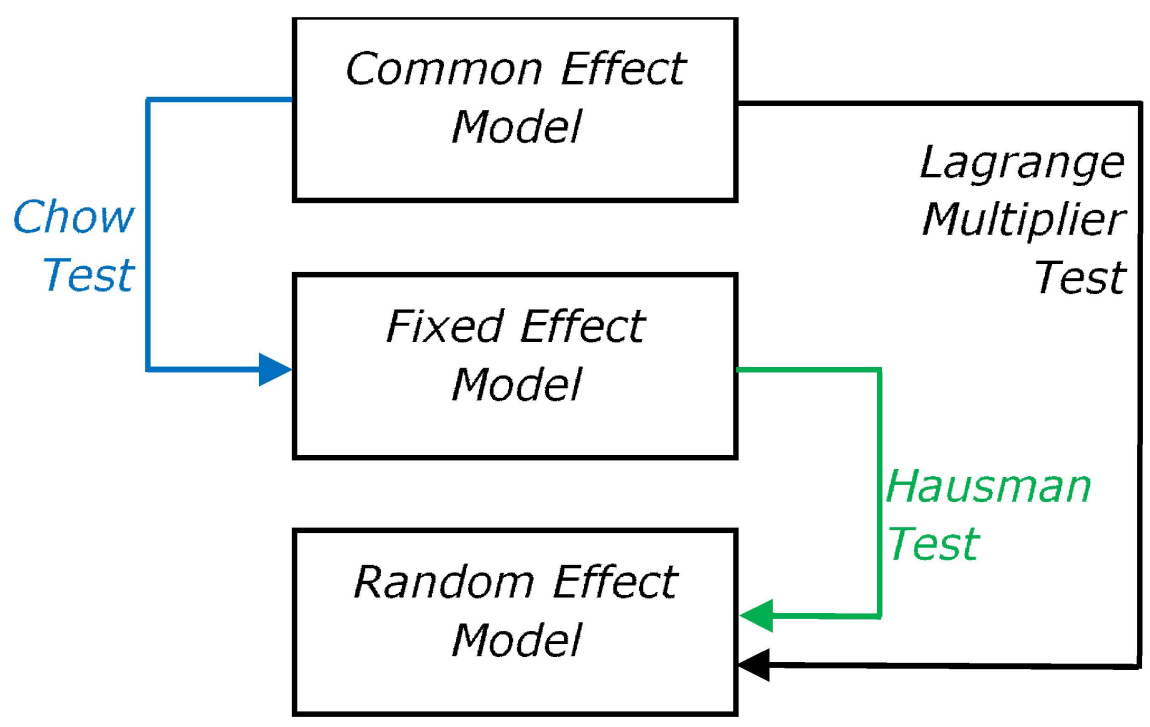

Gambar 3 Pemilihan Model Regresi Data Panel 
Berdasarkan Gambar 3, langkah untuk pemilihan model regresi terbaik adalah 1 ) menentukan model terbaik antara common effect model dengan fixed effect model dengan chow test, 2) jika fixed effect model yang terpilih dilanjutkan dengan hausman test, namun jika common effect model yang terpilih dilanjutkan dengan lagrange multiplier test.

Sumber data penelitian berasal dari Kementerian Pendidikan dan Kebudayaan (Kemendikbud) dan Badan Pusat Statistik (BPS), baik melalui permintaan secara tertulis maupun data yang ada di laman resmi. Variabel dependen menggunakan rata-rata UNBK siswa SMPN tahun 2018-2019. Sedangkan pada variabel independen menggunakan data tahun 2016-2017. Selisih dua tahun ini digunakan untuk mengetahui pengaruh dari variabel independen terhadap variabel dependen melalui proses pembelajaran siswa.

Sampel yang digunakan berjumlah 417 dari 514 kabupaten/kota. Hal ini karena ada beberapa kabupaten/kota yang belum melaksanakan UNBK. Di samping itu, juga tidak tersedianya data realisasi TPG dan tamsil tahun 2016 dan 2017 dari Kemendikbud. Provinsi DKI Jakarta tidak dimasukkan dalam sampel mengingat kewenangan pendidikan dasar dan menengah di DKI Jakarta berada pada tingkat provinsi bukan kabupaten/kota (UU 29 tahun 2007).

Persamaan ekonometrika yang digunakan dalam analisis regresi data panel adalah sebagai berikut.

InNationalExam ${ }_{\mathrm{it}+2}=\beta_{0}+\beta_{1}$ InAllowance ${ }_{\mathrm{it}}+$ $\beta_{2}$ InAdditionalincome ${ }_{\text {it }}+\beta_{3}$ STR $_{\text {it }}+\beta_{4}$ Classes $_{\text {it }}+$ $\beta_{5}$ Bachelor $_{\text {it }}+\beta_{6}$ Poverty $_{\text {it }}+\beta_{7}$ InGRDP $_{\text {it }}+\beta_{8}$ Life $_{\text {it }}+$ $\beta_{9}$ Region $_{i t}+u_{i t}$

dimana, NationalExam: rerata nilai ujian nasional (poin, skala 0-100)

Allowance: tunjangan profesi guru/ jumlah guru PNS SMPN tersertifikasi (juta rupiah)

AdditionalIncome: tambahan penghasilan guru/jumlah guru PNS
STR:

Classes:

Bachelor:

Poverty:

GRDP:

Life:

Region:

u:

SMPN belum tersertifikasi

(juta rupiah)

rasio siswa dengan guru

SMPN (rasio)

rasio siswa dengan rombongan belajar (rasio)

persentase guru PNS

SMPN dengan kualifikasi pendidikan minimal S1 (\%)

presentase penduduk

miskin (\%)

gross regional domestic product/produk domestik regional bruto per kapita

(juta rupiah)

Angka harapan hidup

(tahun)

dummy wilayah (Jawa dan

Bali $=1$, lainnya $=0$ )

residual/error term

Persamaan tersebut menggunakan satuan yang berbeda antara variabel dependen dan independen, rerata nilai ujian nasional dengan skala dan tunjangan profesi guru dengan rupiah. Oleh karena itu, perlu digunakan logaritma natural dalam proses regresi dan koefisien regresi akan sama dalam bentuk persentase.

\section{HASIL DAN PEMBAHASAN}

\section{Analisis Deskriptif}

Statistik deskriptif dari variabel penelitian yang digunakan ditunjukkan pada Tabel 1.

Berdasarkan Tabel 1, rata-rata UNBK SMP Negeri pada tahun 2018 dan 2019 dari sampel penelitian ini adalah 50,5 dengan nilai terendah 36,11 dan nilai tertinggi 81,42. Berdasarkan kategori yang ada pada Prosedur Operasional Standar (POS) Penyelenggaraan Ujian Nasional tahun 2019, rinciannya adalah sebanyak 308 dari 417 kabupaten/kota tahun 2018 dan 332 dari 417 kabupaten/kota tahun 2019 memiliki UNBK pada kategori kurang. Sebanyak 103 dari 417 kabupaten/kota tahun 2018 dan 79 dari 417 kabupaten/kota tahun 2019 dengan kriteria cukup.

Realisasi terendah dan tertinggi dari tunjangan profesi guru dan tambahan 
Didik Biantoro \& Thia Jasmina, Hubungan antara Tunjangan Profesi Guru dan Tambahan Penghasilan dengan Capaian Pembelajaran Siswa Sekolah Menengah Pertama Negeri

Tabel 1 Statistik Deskriptif Data Penelitian

\begin{tabular}{lccccc}
\hline \multicolumn{1}{c}{ Variabel } & Obs* & Mean & Std. Dev & Min & Max \\
\hline Nationalexam (poin) & 834 & 50,50 & 6,99 & 36,11 & 81,42 \\
Allowance (rupiah) & 834 & 42.600 .000 & 7154535 & $198.368,7$ & 68.000 .000 \\
Additional income (rupiah) & 834 & 2.594 .933 & 1.028 .374 & $12.631,58$ & 8.660 .000 \\
STR (rasio) & 834 & 21,37 & 7,33 & 7 & 57 \\
Classes (rasio) & 834 & 27,74 & 4,12 & 18 & 41 \\
Bachelor (\%) & 834 & 92,85 & 4,74 & 67 & 100 \\
Poverty (\%) & 834 & 11,88 & 6,41 & 1,67 & 39,66 \\
GRDP (rupiah) & 834 & 45.200 .000 & 46.400 .000 & 5.999 .000 & 419.000 .000 \\
Life (tahun) & 834 & 69,09 & 3,45 & 55,90 & 79,47 \\
Region & 834 & $24,94 * *$ & 0.43 & 0 & 1 \\
\hline
\end{tabular}

Sumber: diolah penulis

* Jumlah observasi dalam penelitian ini adalah 417 kabupaten/kota untuk data 2 tahun

** Persentase data dummy sebesar $24.94 \%$ untuk variabel region yang nilainya 1 (Jawa dan Bali)

penghasilan di 417 kabupaten/kota tahun 2016 dan 2017 memiliki perbedaan yang cukup besar (lihat Tabel 1). Menurut Kemendikbud (2020), hal ini disebabkan beberapa permasalahan dalam penyaluran tunjangan profesi guru terutama masalah data. Data guru yang di-input operator sekolah tidak sinkron dengan Data Pokok Pendidikan (Dapodik) sehingga menyebabkan data menjadi tidak valid. Akibatnya, nama guru tidak tercantum sebagai penerima tunjangan dalam Surat Keputusan Tunjangan Profesi (SKTP) yang terbit setiap semester dengan konsekuensi pemerintah tidak berwenang menyalurkan tunjangan tersebut, meskipun sudah dianggarkan sebelumnya. Di samping itu, realisasi tersebut menunjukkan realisasi anggaran tahun yang ada tidak menambahkan jika ada dana yang mengendap pada tahun sebelumnya.

Pada variabel rasio siswa dan guru per kabupaten/kota di Indonesia rata-rata setiap satu guru PNS mengajar 21 siswa SMP Negeri. Rasio tersebut lebih rendah dari rata-rata internasional yaitu 23 (World Bank, 2020). Nilai tertinggi rasio siswa dan guru hingga 57 menunjukkan bahwa di kabupaten/kota tersebut sangat kekurangan guru. Rasio siswa dan rombongan belajar, rata-rata setiap satu rombongan belajar diisi oleh 28 siswa SMP Negeri. Angka rata-rata tersebut masuk dalam kondisi ideal, di mana kondisi ideal rasio siswa dengan rombel tidak lebih dari 32 (Permendikbud no. 22 tahun 2016). Sedangkan persentase guru PNS SMP negeri dengan kualifikasi pendidikan minimal S1 rata-ratanya adalah 92,8\%. Dengan persentase terendah $67 \%$ dan tertinggi hingga $100 \%$. Hal ini menunjukkan bahwa guru di Indonesia sebagian besar sudah berpendidikan sarjana.

Pada variabel kontrol sosial ekonomi, ratarata persentase kemiskinan di Indonesia masih $11,9 \%$. Kemiskinan terendah adalah Kota Tangerang Selatan dengen persentase 1,67\% pada tahun 2016 dan tertinggi Kabupaten Jayawijaya yaitu 39,7\% pada tahun (2016). Produk Domestik Regional Bruto (PDRB) per kapita di kabupaten kota di Indonesia rata-rata Rp 45.200.000,--. Di mana PDRB per kapita tertinggi yaitu Kabupaten Teluk Bintuni Rp 418.765.000,- pada tahun 2017 dan terendah Kabupaten Sarmi yaitu Rp 5.999.000,- pada tahun (2017). Angka harapan hidup di Indonesia rata-rata 69 tahun dengan angka harapan hidup terendah yaitu 55,9 tahun dan tertinggi 79,47 tahun. 
Untuk mengetahui apakah ada perbedaan rata-rata nilai UNBK siswa SMPN dalam wilayah Jawa dan Bali (variabel dummy=1) dengan lainnya (variabel dummy $=0$ ) maka dilakukan uji $t=$ test seperti Tabel 2.

Hasil di atas menunjukkan bahwa $\operatorname{Pr}(|\mathrm{T}|>$ $|t|)=0,0000$ atau kurang dari $a=0,01$, maka bisa dikatakan bahwa ada perbedaan antara

Tabel 2 Hasil Uji T Test pada UNBK siswa SMPN antara Wilayah Jawa-Bali dengan Wilayah di luar Jawa-Bali

\begin{tabular}{|c|c|c|c|c|c|c|}
\hline Group & Obs & Mean & Std. Err. & $\begin{array}{l}\text { Std. } \\
\text { Dev. }\end{array}$ & \multicolumn{2}{|c|}{$\begin{array}{c}\text { [95\% Conf. } \\
\text { Interval] }\end{array}$} \\
\hline 0 & 626 & 48,433 & 0,219 & 5,472 & 48,003 & 48,862 \\
\hline 1 & 208 & 56,734 & 0,510 & 7,358 & 55,728 & 57,740 \\
\hline combined & 834 & 50,503 & 0,242 & 6,988 & 50,028 & 50,978 \\
\hline diff & & $-8,301$ & 0,479 & $-9,243$ & & $-7,359$ \\
\hline \multicolumn{4}{|c|}{$\operatorname{diff}=\operatorname{mean}(0)-\operatorname{mean}(1)$} & & \multicolumn{2}{|c|}{$t=-17,296$} \\
\hline \multicolumn{4}{|c|}{ Ho: diff $=0$} & \multicolumn{3}{|c|}{ degrees of freedom $=832$} \\
\hline \multicolumn{2}{|c|}{ Ha: diff $<0$} & \multicolumn{3}{|c|}{ Ha: diff $!=0$} & \multicolumn{2}{|c|}{ Ha: diff $>0$} \\
\hline \multicolumn{2}{|c|}{$\operatorname{Pr}(\mathrm{T}<\mathrm{t})=0,0000$} & \multicolumn{3}{|c|}{$\operatorname{Pr}(|\mathrm{T}|>|\mathrm{t}|)=0,0000$} & \multicolumn{2}{|c|}{$\operatorname{Pr}(\mathrm{T}>\mathrm{t})=1,0000$} \\
\hline
\end{tabular}

Sumber: olahan penulis

rata-rata nilai UNBK siswa SMPN antara wilayah Jawa dan Bali (sebesar 56,73) dengan wilayah lainnya (sebesar 48,43).

\section{Analisis Hasil Estimasi}

Hasil estimasi model regresi (2) di atas disajikan pada Tabel 3 dengan lima kombinasi model regresi. Regresi pertama (1) menggunakan variabel independen utama saja. Regresi (2) dan (3) ditambahkan variabel kontrol karakteristik sekolah dan beberapa karakteristik sosial ekonomi. Selanjutnya regresi (4) menggunakan semua kontrol karakteristik sekolah dan sosial ekonomi. Terakhir regesi (5) ditambahkan dengan interaksi antara variabel independen utama (Inallowance) dengan variabel dummy wilayah (region) untuk melihat lebih jauh dampak perbedaan TPG terhadap UNBK siswa SMP Negeri antarwilayah (region).

Dari kelima hasil regresi tersebut menunjukkan bahwa realisasi tunjangan profesi guru PNS SMP Negeri (Inallowance) berhubungan positif terhadap hasil UNBK siswa SMP Negeri. Di mana kenaikan realisasi tunjangan profesi guru SMP Negeri sebesar 1\% akan dapat meningkatkan nilai UNBK siswa sebesar 0,03\%.
Hasil penelitian ini sesuai dengan beberapa penelitian sebelumnya yang menunjukkan bahwa ada hubungan positif antara tunjangan prosfesi guru dengan capaian pembelajaran siswa (Jasmina, 2016; Idawati, 2017).

Hasil ini juga sesuai dengan penelitian dari BaKTI (2018) dan Kemendikbud (2019) yang menunjukkan bahwa adanya peningkatan hasil pembelajaran siswa. Tunjangan yang diberikan kepada guru ini bisa meningkatkan kinerjanya (Widinugroho \& Modouw, 2016; Arifah, 2018) atau kompetensinya (Yuliandri \& Tahrun, 2017; Nua, 2020) dan juga kreativitasnya (Parsa, 2017). Peningkatan kompetensi, kinerja, atau kreativitas tersebut yang akhirnya bisa meningkatkan capaian pembelajaran siswa, sesuai dengan penelitian dari Azwar et al. (2015); Pristiawaty (2015); Hapsari \& Prasetio (2017); Mahdalena (2019); Nua (2020); Meiliyani et al., 2021).

Di samping itu, penelitian ini sejalan dengan penelitian di tingkat internasional oleh Goldhaber \& Walch (2012); Goodman \& Turner (2013); Hendricks (2014); Sojourner et al. (2014); Balch \& Springer (2015); Cebula et al. (2015); Hanushek et al. (2018) yang menunjukkan 
Didik Biantoro \& Thia Jasmina, Hubungan antara Tunjangan Profesi Guru dan Tambahan Penghasilan dengan Capaian Pembelajaran Siswa Sekolah Menengah Pertama Negeri

Tabel 3 Hasil Estimasi

\begin{tabular}{|c|c|c|c|c|c|}
\hline VARIABEL & (1) & $(2)$ & (3) & (4) & (5) \\
\hline Inallowance & $\begin{array}{r}0,0286^{* *} \\
(0,0111)\end{array}$ & $\begin{array}{r}0,0315^{* * *} \\
(0,0106)\end{array}$ & $\begin{array}{r}0,0317 * * * \\
(0,0106)\end{array}$ & $\begin{array}{r}0,0316 * * * \\
(0,0106)\end{array}$ & $\begin{array}{r}0,0283 * * \\
(0,0119)\end{array}$ \\
\hline 1.region\#c.c_Inallowance & & & & & $\begin{array}{r}0,0154 \\
(0,0255)\end{array}$ \\
\hline Inadditionalincome & $\begin{array}{r}0,0015 \\
(0,0172)\end{array}$ & $\begin{array}{r}-0,0098 \\
(0,0073)\end{array}$ & $\begin{array}{r}-0,0076 \\
(0,0074)\end{array}$ & $\begin{array}{r}-0,0098 \\
(0,0074)\end{array}$ & $\begin{array}{r}-0,0108 \\
(0,0075)\end{array}$ \\
\hline str & & $\begin{array}{c}-0,002 * * \\
(0,0008)\end{array}$ & $\begin{array}{r}-0,002 * * \\
(0,0008)\end{array}$ & $\begin{array}{c}-0,002 * * \\
(0,0008)\end{array}$ & $\begin{array}{r}-0,002 * * \\
(0,0008)\end{array}$ \\
\hline classes & & $\begin{array}{r}0,0023 \\
(0,0016)\end{array}$ & $\begin{array}{r}0,0027 \\
(0,0017)\end{array}$ & $\begin{array}{r}0,0023 \\
(0,0017)\end{array}$ & $\begin{array}{r}0,0023 \\
(0,0017)\end{array}$ \\
\hline bachelor & & $\begin{array}{c}-0,0019 * \\
(0,0011)\end{array}$ & $\begin{array}{r}-0,0015 \\
(0,0011)\end{array}$ & $\begin{array}{c}-0,0019 * \\
(0,0011)\end{array}$ & $\begin{array}{r}-0,0019 * \\
(0,0011)\end{array}$ \\
\hline poverty & & & $\begin{array}{r}-0,0006 \\
(0,0008)\end{array}$ & $\begin{array}{r}-0,0002 \\
(0,0008)\end{array}$ & $\begin{array}{r}-0,0001 \\
(0,0008)\end{array}$ \\
\hline Ingdrp & & $\begin{array}{r}0,0269 * * * \\
(0,008)\end{array}$ & & $\begin{array}{r}0,0267 * * * \\
(0,0081)\end{array}$ & $\begin{array}{r}0,0267 * * * \\
(0,0081)\end{array}$ \\
\hline life & & $\begin{array}{r}0,0096 * * * \\
(0,0017)\end{array}$ & $\begin{array}{r}0,0106 * * * \\
(0,0018)\end{array}$ & $\begin{array}{r}0,0095 * * * \\
(0,0018)\end{array}$ & $\begin{array}{r}0,0094 * * * \\
(0,0018)\end{array}$ \\
\hline region & & $\begin{array}{r}0,121 * * * \\
(0,0144)\end{array}$ & $\begin{array}{r}0,110 * * * \\
(0,0143)\end{array}$ & $\begin{array}{r}0,121 * * * \\
(0,0145)\end{array}$ & $\begin{array}{r}0,120 * * * \\
(0,0146)\end{array}$ \\
\hline Constant & $\begin{array}{r}3,389 * * * \\
(0,278)\end{array}$ & $\begin{array}{r}2,500 * * * \\
(0,257)\end{array}$ & $\begin{array}{r}2,826 * * * \\
(0,254)\end{array}$ & $\begin{array}{r}2,514 * * * \\
(0,270)\end{array}$ & $\begin{array}{r}3,083 * * * \\
(0,208)\end{array}$ \\
\hline Observations & 834 & 834 & 834 & 834 & 834 \\
\hline Number of district & 417 & 417 & 417 & 417 & 417 \\
\hline R-Squared & 0,013 & & & & \\
\hline \multicolumn{6}{|c|}{$\begin{array}{l}\text { Standard errors in parentheses } \\
* * * p<0,01, * * p<0,05, * p<0,1\end{array}$} \\
\hline
\end{tabular}

Sumber: Olahan penulis

bahwa insentif atau peningkatan gaji berhubungan positif terhadap skor tes siswa.

Peningkatan capaian pembelajaran siswa dipengaruhi oleh beberapa faktor, salah satunya kompetensi maupun kinerja/ produktivitas guru (Metzler \& Woessmann, 2012; Kunter et al, 2013, Chetty et al., 2014). Guru yang mendapat tunjangan profesi bisa memanfaatkan tunjangan tersebut untuk peningkatan kompetensi dan kesejahteraan sehingga bisa meningkatkan kinerja mereka. Peningkatan kinerja guru bisa dilihat dari syarat penyaluran tunjangan profesi. Syarat tunjangan guru yang bisa diterima adalah memiliki nilai hasil penilaian kinerja minimal baik dan juga memenuhi beban kerja guru berdasarkan Peraturan Pemerintah Nomor 19 Tahun 2017 (24 jam hingga 40 jam mengajar dalam satu minggu). Sehingga untuk mendapatkan tunjangannya guru harus memenuhi syarat tersebut.

Penilaian kinerja guru berdasarkan Permenpan Nomor 16 Tahun 2009, di samping kompetensi, guru juga harus memasukkan unsur capaian pembelajaran siswa. Guru harus menilai dan melakukan evaluasi proses dan hasil belajar, analisis hasil penilaian pembelajaran, dan mengadakan perbaikan serta pengayaan. Hal ini menunjukkan bahwa capaian pembelajaran siswa harus baik agar tunjangan profesi guru dapat diterima. Dengan adanya ikatan tersebut, tunjangan profesi guru sangat memengaruhi kinerja/produktivitas guru. Di samping itu, syarat lainnya adalah guru harus aktif mengajar sesuai dengan Sertifikat Pendidik dan kompetensi yang 
dimilikinya. Akhirnya proses pembelajaran berjalan lebih baik dan capaian pembelajaran siswa bisa meningkat. Guru juga tidak boleh terikat sebagai tenaga tetap pada instansi selain satuan pendidikan tempat bertugas agar tunjangan profesi bisa diberikan. Dengan adanya ikatan tersebut, kenaikan gaji guru dalam hal ini tunjangan profesi guru, akan meningkatkan produktivitas (Borjas, 2016).

Akan tetapi hasil penelitian tersebut berbeda dengan beberapa penelitian sebelumnya di Indonesia. Di mana tunjangan profesi guru tidak berhubungan dengan hasil belajar siswa (Ree el al., 2018; Kusumawardhani, 2017; Astiti et al., 2018). Begitu juga dengan penelitian tingkat internasional yang mengungkap bahwa insentif/kenaikan gaji guru tidak diiringi oleh peningkatan hasil belajar/prestasi siswa (Fryer, 2013; Cowan \& Goldhaber, 2018; Pugatch \& Schroeder, 2018; Yesilýrmak, 2019; Chelwa et al., 2019; dan Speroni et al., 2020).

Hasil yang berbeda diperoleh untuk variabel realisasi tambahan penghasilan (Inadditionalincome). Realisasi tambahan penghasilan bagi guru tidak berhubungan dengan hasil UNBK siswa SMP. Tambahan penghasilan merupakan upaya pemerintah memberikan tunjangan bagi guru PNS yang belum tersertifikasi agar dapat meningkatkan gairah/semangat kerja dan kesejahteraan bagi Guru PNSD. Perbedaan besarnya tunjangan dan tambahan penghasilan yang sangat besar antara guru yang sudah tersertifikasi dengan yang belum dapat menjadi faktor yang menyebabkan tidak ada hubungannya tersebut. Guru yang tersertifikasi mendapatkan tunjangan sebesar 1 kali gaji pokok per bulan, sedangkan yang belum hanya Rp 250.000,- per bulan. Meskipun demikian guru PNSD yang belum bersertifikat pendidik harus tetap memenuhi beban kerja yang sama dengan yang bersertifikat berdasarkan PP Nomor 19 Tahun 2017 (24 jam hingga 40 jam mengajar dalam satu minggu). Penghasilan yang berbeda namun dengan beban kerja yang sama dalam pelaksanaan pembelajaran akan lebih meningkat kompetensi bagi guru yang mendapatkan penghasilan lebih dan berkorelasi positif terhadap capaian pembelajaran siswa (Hanushek el al., 2018).

Hasil dari variabel kontrol karakteristik sekolah dari keempat kombinasi model tersebut, menunjukkan bahwa variabel rasio siswa dan guru berhubungan negatif terhadap hasil UNBK siswa SMP Negeri. Jika rasio siswa dan guru meningkat sebesar satu unit, nilai UNBK siswa SMP Negeri akan turun sebesar 0,2\%. Dari hasil penelitian ini, rasio siswa dan guru per kabupaten/kota di Indonesia rata-rata setiap satu guru PNS mengajar 21 siswa SMP Negeri dengan standar deviasi 7,33. Nilai standar deviasi yang lebih rendah dibandingkan rata-rata menunjukkan bahwa data tersebar secara merata. Pada tahun 2016 ada 180 kabupaten/ kota yang di atas rata-rata atau $43,17 \%$. Sedangkan pada tahun 2017 ada 179 kabupaten/kota yang di atas rata-rata atau $42,93 \%$. Rata-rata rasio siswa dan guru tersebut lebih rendah dari rata-rata internasional sebesar 23 (World Bank, 2020).

Di sisi lain, nilai tertinggi rasio siswa dan guru hingga 57, menunjukkan bahwa di kabupaten/kota tersebut sangat kekurangan guru. Menurut UNESCO (2006) batas maksimum rasio siswa dan guru adalah 40 . Jadi, jika suatu negara memiliki rasio guru-siswa lebih tinggi dari 40, diharapkan menurunkan rasio ke tingkat ini. Jika rasio murid-guru sudah di bawah 40, angka ini harus dipertahankan. Data yang ada menunjukkan bahwa tahun 2016 rasio siswa dan guru di atas 40 di 11 kabupaten/kota dan demikian juga pada tahun 2017 di 11 kabupaten/ kota. Hal ini harus menjadi perhatian serius dari pemerintah untuk menurunkan rasio siswa dan guru agar kualitas pendidikan lebih baik.

Variabel rasio siswa dan rombongan belajar tidak ada hubungannya dengan hasil UNBK siswa SMP Negeri. Hasil ini tidak sesuai dengan penelitian Mahdalena (2019). Dalam penelitian 
Didik Biantoro \& Thia Jasmina, Hubungan antara Tunjangan Profesi Guru dan Tambahan Penghasilan dengan Capaian Pembelajaran Siswa Sekolah Menengah Pertama Negeri

tersebut, rasio siswa dan rombongan belajar rata-rata setiap satu rombongan belajar diisi oleh 28 siswa SMP Negeri dengan standar deviasi 4,12 . Nilai standar deviasi yang lebih rendah dibandingkan rata-rata menunjukkan bahwa data tersebar secara merata. Angka rata-rata tersebut sudah masuk dalam kondisi ideal yaitu kondisi ideal rasio siswa dengan rombel tidak lebih dari 32 (Permendikbud Nomor 22 Tahun 2016). Jika dilihat dari rasio siswa dan rombel per kabupaten/kota, tahun 2016 ada 66 kabupaten/kota yang rasionya di atas 32, sedangkan tahun 2017 ada 46 kabupaten/ kota yang rasionya di atas 32 .

Variabel persentase guru PNS SMPN dengan kualifikasi pendidikan S-1 mempunyai hubungan yang negatif dengan nilai UNBK siswa SMPN. Kenaikan jumlah $1 \%$ guru yang berkualifikasi S1 akan menurunkan nilai UNBK siswa sebesar 0,002\%. Hasil penelitian ini menunjukkan bahwa perekrutan guru PNS SMPN berdasarkan kualifikasi pendidikan sebagai syarat menjadi PNS masih bermasalah. Menurut Revina \& Huang (2020), rendahnya kualitas guru disebabkan oleh proses perekrutan guru yang hanya memenuhi tuntutan kebutuhan dalam aparatur sipil negara dengan kriteria harus S-1 bukan berfokus pada pemilihan tenaga pendidik yang profesional. Hal ini disebabkan sistem rekrutmen guru ASN atau PNS saat ini masih belum bisa mengakomodir minat atau panggilan jiwa untuk mengajar. Di samping itu, perekrutan tidak melihat kebutuhan guru di lapangan tetapi hanya berdasarkan alokasi anggaran pendidikan di Indonesia. Perekrutan guru PNS berpendidikan minimal S1 hanya berdasarkan tes wawasan kebangsaan dan pengetahuan umum, bukan kompetensi mengajar. Dengan demikian, kualifikasi guru S1 belum menjamin capaian pembelajaran siswa yang meningkat, bahkan bisa menurunkan capaian pembelajaran siswa.

Pada variabel independen kontrol karakteristik sosial ekonomi menunjukkan bahwa hanya PDRB per kapita dan angka harapan hidup yang berhubungan positif dengan hasil UNBK siswa SMP Negeri. Kenaikan 1\% pada PDRB per kapita akan meningkatkan nilai UNBK siswa SMP sebesar 0,027\% sedangkan kenaikan 1 tahun angka harapan hidup akan meningkatkan nilai UNBK siswa SMPN sebesar 0,96\%. Hasil ini sesuai dengan penelitian Jasmina (2016) bahwa rasio harapan hidup memiliki hubungan yang positif dengan capaian pembelajaran siswa. Hal ini menunjukkan bahwa kesehatan yang lebih baik akan bisa meningkatkan capaian pembelajaran siswa. Kenaikan PDRB per kapita juga menunjukkan bahwa di kabupaten/kota terjadi peningkatan pertumbuhan ekonomi sehingga masyarakat lebih makmur. Hasil ini tidak sesuai dengan pendapat Jasmina (2016) dan Canales \& Maldonado (2018), namun dari segi arah sama yaitu negatif.

Pada variabel independen kontrol dummy wilayah Jawa dan Bali adalah 1 dan lainnya 0. Hal ini menunjukkan bahwa siswa SMPN di wilayah Jawa dan Bali memiliki nilai UNBK 0.12 lebih tinggi daripada siswa SMPN di wilayah lainnya. Hal ini terbukti dari hasil UNBK tahun 2018 dan 2019 yang menunjukkan bahwa beberapa wilayah Jawa dan Bali masuk kategori baik.

Hasil interaksi antara tunjangan profesi guru dengan dummy wilayah menunjukkan hasil yang tidak signifikan. Jika dari dummy wilayah tersebut dikelompokkan berdasarkan tiga kategori nilai UNBK yaitu rendah (1), sedang (2), dan tinggi (3), akan menghasilkan perbedaan terhadap prediksi rata-rata hasil UN. Hasil tersebut adalah sebagai terlihat pada Tabel 4.

Hasil di atas menunjukkan bahwa ada perbedaan hubungan antara tunjangan profesi guru antara daerah Jawa dan Bali dengan daerah luar Jawa dan Bali dengan prediksi capaian pembelajaran siswa. Pada realisasi tunjangan profesi guru dengan kategori rendah (1), di daerah Jawa-Bali dan Iuar Jawa-Bali masih memiliki prediksi rata-rata hasil UNBK yang relatif 
Tabel 4 Prediksi Hasil Rata-Rata Ujian Nasional Berdasarkan Interaksi antara Tunjangan Profesi Guru dengan Wilayah Jawa Bali (1) dan Luar Jawa Bali (0)

\begin{tabular}{cc|cccccc}
\hline & & \multicolumn{2}{|c}{ Delta-method } \\
& & Margin & Std. Err. & $\mathrm{z}$ & $\mathrm{P}>|\mathrm{z}|$ & {$[95 \%$ Conf. Interval] } \\
\hline -at\# region & & & & & & \\
1 & 0 & 41,12 & 3,739 & 11 & 0,000 & 33,7878 & 48,4446 \\
1 & 1 & 40,06 & 7,2866 & 5,5 & 0,000 & 25,7759 & 54,339 \\
2 & 0 & 48,85 & 0,3039 & 160,77 & 0,000 & 48,2582 & 49,4493 \\
2 & 1 & 55,35 & 0,6303 & 87,82 & 0,000 & 54,115 & 56,5856 \\
3 & 0 & 56,59 & 3,7734 & 15 & 0,000 & 49,1956 & 63,9872 \\
3 & 1 & 70,64 & 7,053 & 10,02 & 0,000 & 56,8195 & 84,4668 \\
\hline
\end{tabular}

Sumber: Olahan penulis

sama yaitu sekitar 40. Namun, ketika realisasi kategori sedang (2) menunjukkan hasil yang berbeda cukup jauh yaitu 55,35 dibandingkan dengan 48,85 . Jika realisasi tunjangan profesi guru tinggi (3), lebih besar lagi perbedaan prediksi rata-rata hasil UNBK yaitu 70,64 dibandingkan dengan 56,59. Hasil interaksi antara tunjangan profesi guru dengan dummy wilayah ini juga menunjukkan adanya kesenjangan pengaruh realisasi dari wilayah Jawa-Bali dengan luar Jawa- Bali.

Hasil tersebut berbeda dengan pendapat Jasmina (2016), bahwa variabel yang dipakai adalah wilayah barat dan timur yang menunjukkan rata-rata hasil ujian nasional yang tidak memiliki perbedaan. Perbedaan ini bisa disebabkan oleh penggunaan data, karena penelitian ini menggunakan data realisasi sedangkan Jasmina (2016) menggunakan data anggaran. Oleh karena itu, pemerintah pusat maupun daerah harus memperhatikan secara serius untuk meningkatkan realisasinya dan juga mengatasi kesenjangan tersebut. Perbedaan ini juga tercermin dalam hasil uji kompetensi guru (UKG) yang dilaksanakan oleh Kemendikbud (2015). Pada hasil UKG guru SMP menunjukkan bahwa ada 14 provinsi yang hasilnya di atas rata-rata nasional. Dari 14 provinsi tersebut, semua provinsi di wilayah Jawa-Bali termasuk ke dalam kategori di atas rata-rata. Bahkan 3 teratas adalah Provinsi di Jawa yaitu Yogyakarta, Jawa Tengah, dan DKI Jakarta (Kemendikbud, 2015).

\section{SIMPULAN DAN SARAN Simpulan}

Hasil penelitian adanya hubungan positif dari TPG dengan UNBK siswa SMP Negeri menunjukkan bahwa secara tidak langsung realisasi TPG akan meningkatkan kinerja/ produktivitas dan kompetensi guru serta pembelajaran berjalan lebih baik. Sedangkan tambahan penghasilan guru yang tidak berhubungan dengan UNBK siswa SMP menunjukkan bahwa besaran insentif untuk guru PNSD yang belum tersertifikasi tidak terlalu membawa perubahan dalam peningkatan capaian pembelajaran siswa.

Hubungan yang negatif antara peningkatan rasio siswa dengan hasil UNBK menunjukkan bahwa semakin banyak siswa yang diajar akan menyebabkan pembelajaran kurang efektif. Di samping itu, hubungan negatif dari kualifikasi S-1 menunjukkan bahwa seleksi Calon Aparatur Sipil Negara (CASN) masih belum optimal. Hubungan yang positif antara produk regional bruto per kapita dan angka harapan hidup dengan hasil UNBK menunjukkan bahwa daerah dengan kategori ekonomi dan kesehatan yang baik akan dapat meningkatkan capaian pembelajaran siswa dibandingkan dengan daerah yang kurang baik. Sejalan dengan peningkatan realisasi TPG, rasio siswa dengan guru dan perekrutan CASN guru harus dioptimalkan agar dapat meningkatkan capaian pembelajaran siswa. Di samping itu, faktor ekonomi dan kesehatan suatu daerah juga harus ditingkatkan. 
Didik Biantoro \& Thia Jasmina, Hubungan antara Tunjangan Profesi Guru dan Tambahan Penghasilan dengan Capaian Pembelajaran Siswa Sekolah Menengah Pertama Negeri

\section{Saran}

Berdasarkan hasil penelitian, ada beberapa saran kebijakan untuk meningkatkan capaian belajar siswa antara lain.

1. Pemerintah kabupaten/kota perlu tepat waktu dalam merealisasikan pembayaran TPG sehingga realisasi akan meningkat;

2. Pemerintah perlu mempertimbangkan mekanisme baru terkait pembayaran tunjangan untuk peningkatan kompetensi guru dengan cara pencairan persentase TPG;

3. Pemerintah pusat dan daerah perlu berkoordinasi setiap tahun melalui monitoring dan evaluasi tunjangan guru untuk menjaga kualitas guru;

4. Pemerintah perlu mempertimbangkan kompetensi pengetahuan dan pedagogi guru dengan kualifikasi S-1 dalam seleksi guru sebagai Calon Aparatur Sipil Negara (CASN). Dalam penelitian ini ada beberapa keterbatasan yang perlu diperbaiki jika ada penelitian yang sama pada masa mendatang yaitu:

1. Penelitian ini hanya memasukkan sampel kabupaten/kota yang melaksanakan UNBK dan melaporkan realisasi tunjangan profesi maupun tambahan penghasilan kepada Kemendikbud.

2. Penelitian ini menggunakan data kabupaten/ kota sehingga tidak bisa menganalisis karakteristik individu. Diharapkan penelitian selanjutnya dapat menganalisis pada level individu, sehingga karakteristik individu yang berbeda dapat dianalisis sebagai faktor yang memengaruhi capaian pembelajaran siswa.

3. Faktor-faktor yang memengaruhi capaian pembelajaran siswa dalam penelitian ini terbatas dari sisi guru, tidak memasukkan faktor internal siswa terkait intelegensi, bakat, minat, dan motivasi dan juga faktor eksternal lainnya seperti sarana prasarana, fasilitas sekolah, aktivitas siswa, dan lain sebagainya.

4. Penelitian ini tidak meneliti secara langsung korelasi antara tunjangan profesi guru dan tambahan penghasilan guru dengan peningkatan kompetensi maupun kinerja guru. Dalam penelitian diasumsikan bahwa kenaikan tunjangan profesional guru akan meningkatkan kompetensi guru yang akan meningkatkan capaian pembelajaran siswa. Analisis kuantitatif lebih lanjut dengan twosteps regression dapat dilakukan untuk melihat hubungan antara tunjangan guru, kompetensi guru, dan hasil pembelajaran siswa.

5. Waktu penelitian ini terbatas hanya dua tahun (2018 dan 2019) dan tidak menjelaskan trend secara keseluruhan ataupun longitudinal study dari semenjak tunjangan profesi guru maupun tambahan penghasilan diberikan. Oleh karena itu, penelitian selanjutnya bisa dengan menambah data dari segi waktu agar dapat melihat trend secara keseluruhan.

\section{PUSTAKA ACUAN}

Amnatu, F., Aunurrahman, \& Suib, M. Implementasi kebijakan dalam memberikan tambahan penghasilan berdasarkan beban kerja kepada guru SMP di daerah terpencil sekecamatan Lembah Bawang. Jurnal Pendidikan dan Pembelajaran Khatulistiwa, 2(12), 1-20.

Arifah, I. (2018). Pengaruh tunjangan profesi dan kompetensi guru terhadap kinerja guru sekolah dasar di Kecamatan Ciruas. Jurnal Pendidikan, 19(1), 1-11. doi.org/10.33830/ jp.v19i1.139.2018.

Astiti, N.W.P., Wilian, S., \& Sridana, N. (2018). The impacts of professional allowances and working motivation towards teachers' working performance at senior high schools in 
Mataram, Indonesia. IOSR Journal of Research \& Method in Education, 8(3), 69-76. doi: 10.9790/7388-0803046976.

Azwar, K., Yusrizal, \& Ar, M. (2015). Pengaruh sertifikasi dan kinerja guru terhadap peningkatan hasil belajar siswa di SMP Negeri 2 Banda Aceh. Jurnal Administrasi Pendidikan, 3(2), 138147.

BaKTI. (2018). Laporan pelaksanaan rintisan kinerja dan akuntabilitas guru (KIAT Guru). Jakarta: Bursa Pengetahuan Kawasan Timur Indonesia (BaKTI).

Balch, R., \& Springer, M.G. (2015). Performance pay, test scores, and student learning objectives. Economics of Education Review, 44, 114-125. doi.org/10.1016/ j.econedurev.2014.11.002.

Basuki, A.T. (2014). Regresi Model PAM, ECM, dan Data Panel Dengan Eviews 7. Yogyakarta: Danisa Media.

Borjas, G.J. (2016). Labor economics ( $7^{\text {th }}$ ed). New York: McGraw-Hill Education.

Badan Pusat Statistik. (2019). Produk domestik regional bruto kabupaten/kota di Indonesia Tahun 2015-2019. Jakarta: Badan Pusat Statistik.

Badan Pusat Statistik. (2020). Persentase penduduk miskin menurut kabupaten/kota (Persen). https://www.bps.go.id/indicator/23/621/3/persentase-penduduk-miskin-menurutkabupaten-kota.html. diakses tanggal 2 Februari 2021

Badan Pusat Statistik. (2020). Tabel angka harapan hidup (metode baru). https:// ipm.bps.go.id/data/nasional. diakses tanggal 2 Februari 2021.

Cebula, R.J., Jr., F.G.M., Montez, M.A. (2015). Teachers'salaries and human capital, and their effects on academic performance: An institution-level analysis of Los Angeles County high schools. Journal of Economics and Finance, 39(2), 347-356. DOI:10.1007/s12197013-9261-3.

Chelwa, G., Pellicer M., \& Maboshe, M. (2019). Teacher pay and educational outcomes: Evidence from the rural hardship allowance in Zambia. South African Journal of economics, 87(3), 255-282. doi.org/10.1111/saje.12227.

Chetty, R., Friedman, J.N., \& Rockoff, J.E. (2014). Measuring the impacts of teachers II: teacher value-added and student outcomes in adulthood. American Economic Review, 104 (9), 2633-2679. doi:10.1257/aer.104.9.2633.

Cowan, J., \& Goldhaber. (2018). Do bonuses affect teacher staffing and student achievement in high-poverty schools? Evidence from an incentive for national board certified teachers in washington state. Economics of Education Review, 65, 138-152. doi.org/10.1016/ j.econedurev.2018.06.010.

Fryer, R. (2013). Teacher incentives and student achievement: Evidence from New York City public schools. Journal of Labor Economics, 31(2), 373-427. doi.org/10.1086/667757.

Glewwe, P., Lambert, S., \& Chen, Q. (2020). Education production functions: Updated evidence from developing countries. Dalam Steve Bradley and Colin Green (Eds), The economics of education: A comprehensive overview Second Edition. London: Academic Press.

Goldhaber, D., \& Walch, J. (2012). Strategic pay reform: A student outcomes-based evaluation of Denver's ProComp teacher pay initiative. Economics of Education Review, 31(6), 1067- 
Didik Biantoro \& Thia Jasmina, Hubungan antara Tunjangan Profesi Guru dan Tambahan Penghasilan dengan Capaian Pembelajaran Siswa Sekolah Menengah Pertama Negeri

1083. doi.org/10.1016/j.econedurev.2012.06.007.

Goodman, S.F., \& Turner, L.J. (2013). The design of teacher incentive pay and educational outcomes: Evidence from The New York City Bonus Program. Journal of Labor Economics, 31(2), 409-420. doi.org/10.1086/668676.

Gujarati, D., \& Porter, D.C. (2009). Basic Econometrics ( $5^{\text {th }}$ ed). New York: McGraw Hill Book Company.

Hanushek, E.A. (2013). Economic growth in developing countries: The role of human capital. Economics of Education Review, 37, 204-212. doi.org/10.1016/ j.econedurev.2013.04.005.

Hanushek, E.A., Piopiunik, M., \& Wiederhold, S. (2018). The value of smarter teachers: International evidence on teacher cognitive skills and student performance. The Journal of Human Resources, 54(4), 857-899. doi:10.3368/jhr.55.1.0317.8619R1.

Hapsari, D.W., \& Prasetio, A.P. (2017). Pengaruh Kompetensi Guru Terhadap Prestasi Belajar Siswa SMK Negeri 2 Bawang. E-Proceeding of Management, 4(1), 269-274.

Hendricks, M.D. (2014). Does It Pay to Pay Teachers More? Evidence from Texas. Journal of Public Economics, 109, 50-63. doi:10.1016/j.jpubeco.2013.11.001.

Idawati. (2017). Pengaruh Dana Sertifikasi dan Dana Alokasi Khusus Terhadap Hasil Belajar Siswa (Survei Pada Sekolah Menengah Di Kota Palu). Jurnal Katalogis, 5(6), 51-62.

Jasmina, T. (2016). Public spending and learning outcomes of basic education at the district level in Indonesia. Economics and Finance in Indonesia, 62(3), 180-190. doi.org/ 10.47291/efi.v62i3.556.

Jones, M.D. (2013). Teacher behavior under performance pay incentives. Economics of Education Review, 37, 148-164. doi.org/10.1016/j.econedurev.2013.09.005.

Kementerian Pendidikan dan Kebudayaan. (2021). Data UKG. https://npd.kemdikbud.go.id/ ?appid=ukg. diakses tanggal 13 Desember 2021

Kementerian Pendidikan dan Kebudayaan. (2016). Peraturan Menteri Pendidikan dan Kebudayaan Republik Indonesia Nomor 22 Tahun 2016 Tentang Standar Proses Pendidikan Dasar dan Menengah. Jakarta: Direktorat Jenderal Pendidikan Dasar dan Menengah.

Kementerian Pendidikan dan Kebudayaan. (2019). Peraturan Menteri Pendidikan dan Kebudayaan Republik Indonesia Nomor 19 Tahun 2019 Tentang Petunjuk Teknis Penyaluran Tunjangan Profesi, Tunjangan Khusus, dan Tambahan Penghasilan Guru Pegawai Negeri Sipil Daerah. Jakarta: Direktorat Jenderal Guru dan Tenaga Kependidikan.

Kementerian Pendidikan dan Kebudayaan. (2019). Laporan Pemantauan dan Evaluasi Tunjangan Profesi Guru (TPG) Tahun (2019). Jakarta: Direktorat Pembinaan Guru Pendidikan Dasar Direktorat Jenderal Guru dan Tenaga Kependidikan.

Kementerian Pendidikan dan Kebudayaan. (2019). Tabel Statistik Sekolah Menengah Pertama (SMP). http://statistik.data.kemdikbud.go.id/index.php/page/smp. diakses tanggal 5 April 2021.

Kementerian Pendidikan dan Kebudayaan. (2020). Masalah dan solusi persoalan data penerima dan pembayaran tunjangan profesi guru. https://jendela.kemdikbud.go.id/v2/fokus/ detail/masalah-dan-solusi-persoalan-data-penerima-dan-pembayaran-tunjangan-profesiguru. diakses tanggal 2 Februari 2021. 
Kementerian Pendidikan dan Kebudayaan. (2021). Laporan Hasil Ujian Nasional https:// hasilun.puspendik.kemdikbud.go.id/. diakses tanggal 2 Februari 2021

Kementerian Pendayagunaan Aparatur Negara dan Reformasi Birokrasi. (2009). Peraturan Menteri Negara Pendayagunaan Aparatur Negara Dan Reformasi Birokrasi Nomor 16 Tahun 2009 Tentang Jabatan Fungsional Guru Dan Angka Kreditnya. Jakarta: Badan Kepegawaian Negara.

Kunter, M., Klusmann, U., Baumert, J., Richter, D., Voss, T., \& Hachfeld, A. (2013). Professional competence of teachers: Effects on instructional quality and student development. Journal of Educational Psychology, 105(3), 805-820. doi.org/10.1037/a0032583.

Kusumawardhani, P.N. (2017). Does teacher certification program lead to better quality teachers? Evidence from Indonesia. Education Economics, Taylor \& Francis Journals, 25(6), 590-618. https://doi.org/10.1080/09645292.2017.1329405.

Mahdalena, Y.T. (2019). Pengaruh banyaknya guru yang berkualifikasi dan ukuran rombongan belajar terhadap nilai ujian nasional pada SMP di DKI Jakarta. Tesis. Jakarta: Universitas Pelita Harapan.

Meiliyani, R., Fitria, H., \& Puspita, Y. (2021). Pengaruh sertifikasi dan kinerja guru terhadap prestasi belajar siswa. Journal of Education Research, 2(1), 6-14. doi.org/10.37985/ jer.v2i1.39.

Metzler, J., \& Woessmann, L. (2012). The impact of teacher subject knowledge on student achievement: Evidence from within-teacher within-student variation. Journal of Development Economics, 99(2), 486-496. doi.org/10.1016/j.jdeveco.2012.06.002.

Nua, F.M. (2020). Tunjangan profesi guru sebagai upaya peningkatan kompetensi guru dan karakter peserta didik. Jurnal IImu Manajemen, 9(2), 250-266. doi.org/10.32503/ revitalisasi.v9i2.1369.

Parsa, I.M. (2017). Evaluation study effect of allowances and job creativity - The performance of the teacher in secondary vocational school province of East Nusa Tenggara. International Education Studies, 10 (8), 96-107. doi:10.5539/ies.v10n8p96.

Pristiawaty, E. (2015). Kompetensi profesional guru yang bersertifikasi dapat meningkatkan prestasi belajar siswa. Jurnal Edukasi Kultura, 1(1), 29-44. doi.org/10.24114/ kultura.v1i1.1786.

Pugatch, T., \& Schroeder, E. (2018). Teacher pay and student performance: Evidence from the Gambian hardship allowance. Journal Of Development Effectiveness, 10(2), 249-276. Doi: 10.1080/19439342.2018.1452778.

Ree, J.D., Muralidharan, K., Pradhan, M., \& Rogers, H. (2018). Double for Nothing? Experimental evidence on the impact of an unconditional teacher salary increase on student performance in Indonesia. The Quarterly Journal of Economics, 133(2), 993-1039, 9931039. Doi:10.1093/qje/qjx040.

Republik Indonesia. (2005). Undang-undang Republik Indonesia Nomor 14 Tahun 2005 Tentang Guru dan Dosen. Jakarta: Kementerian Pendidikan dan Kebudayaan.

Republik Indonesia. (2007). Undang-Undang Republik Indonesia Nomor 29 Tahun 2007 Tentang Pemerintahan Provinsi Daerah Khusus Ibukota Jakarta Sebagai Ibukota Negara Kesatuan Republik Indonesia. Jakarta: Provinsi Daerah Khusus Ibukota Jakarta. 
Didik Biantoro \& Thia Jasmina, Hubungan antara Tunjangan Profesi Guru dan Tambahan Penghasilan dengan Capaian Pembelajaran Siswa Sekolah Menengah Pertama Negeri

Republik Indonesia. (2009). Peraturan Pemerintah Republik Indonesia Nomor 41 Tahun 2009 Tentang Tunjangan Profesi Guru Dan Dosen, Tunjangan Khusus Guru dan Dosen, Serta Tunjangan Kehormatan Profesor. Jakarta: Kementerian Pendidikan dan Kebudayaan.

Republik Indonesia. (2009). Peraturan Presiden Republik Indonesia Nomor 52 Tahun 2009 Tentang Tambahan Penghasilan Bagi Guru Pegawai Negeri Sipil. Jakarta: Kementerian Pendidikan dan Kebudayaan. Republik Indonesia. (2014). Undang-undang Republik Indonesia Nomor 23 Tahun 2014 Tentang Pemerintahan Daerah (Tambahan Lembaran Negara Republik Indonesia Nomor 5587). Jakarta: Pemerintah Daerah Provinsi, Kabupaten, dan Kota.

Revina, S., \& Huang, A. 25 Agustus (2020). Proses rekrutmen sebagai ASN membuat guru di Indonesia berkualitas rendah. https://theconversation.com/proses-rekrutmen-sebagaiasn-membuat-guru-di-indonesia-berkualitas-rendah-143443. diakses 19 Mei 2021.

Speroni, C., Wellington, A., Burkander, P., Chiang, H., Herrmann, M., \& Hallgren, K. (2020). Do educator performance incentives help students? Evidence from the teacher incentive fund national evaluation. Journal of Labor Economics, 38(3), 843-872. doi.org/10.1086/ 706059.

Sojourner, A.J., Mykerezi, E., \& West, K.L. (2014). Teacher pay reform and productivity: Panel data evidence from adoptions of Q-Comp in Minnesota. Journal of Human Resources, 49(4), 945-981. doi.org/10.1353/jhr.2014.0029.

UNESCO. (2006). Teachers and educational quality: Monitoring global needs for (2015). Montreal: UNESCO Institute for Statistics.

Widinugroho, A., \& Modouw, J. (2016). Efektivitas pemberian tunjangan sertifikasi guru terhadap kinerja guru IPA dan prestasi belajar IPA siswa SMP/MTs di Jayapura. Jurnal IImu Pendidikan Indonesia, 4(1), 1-15.

World Bank. February (2020). Pupil-teacher ratio, primary. https://data.worldbank.org/indicator. Diakses tanggal 5 April 2021.

Yesilýrmak, M. (2019). Bonus pay for teachers, spatial sorting, and student achievement. European Journal Of Political Economy, 59, 129-158. doi.org/10.1016/ j.ejpoleco.2019.02.004.

Yuliandri, J., \& Tahrun. (2017). Tunjangan profesi sebagai upaya peningkatan kompetensi guru untuk mewujudkan guru profesional. Jurnal Manajemen, Kepemimpinan, dan Supervisi Pendidikan, 2(1), 115-127. doi.org/10.31851/jmksp.v6i1.3961. 